\title{
Representações sociais e identidade docente: um estudo de caso na formação de professores em ciências sociais da UFRN
}

\author{
Elda Silva do Nascimento Melo* \\ Karla Michelle de Oliveira**
}

\section{Resumo}

A presença hodierna da Sociologia na educação básica brasileira é um elemento novo para os sujeitos a ela relacionados e, para o grupo de licenciando(a)s do curso de Ciências Sociais da Universidade Federal do Rio Grande do Norte (UFRN), a situação não é diferente. Com o intuito de compreender como os elementos apreendidos durante a formação inicial de professores influenciam o processo de construção identitária, investigou-se as representações sociais que esses sujeitos constroem acerca da identidade docente, buscando compreender como eles representam os professores de Sociologia. Para tanto, procedeu-se a uma comparação entre os elementos que compuseram os núcleos centrais das representações sociais dos licenciandos ingressantes e dos estagiários do referido curso. Adotou-se a Teoria das Representações Sociais e a Abordagem Estrutural como aporte teórico, e a Técnica de Associação Livre de Palavras como recurso metodológico. Ao se proceder à análise dos dados obtidos durante a pesquisa, tornou-se evidente que a memória desempenha um papel crucial nos processos de construção representacional e identitário, pois a familiaridade com a disciplina de Sociologia no Ensino Médio trouxe novos e importantes elementos para a composição do perfil dos atuais ingressantes na licenciatura investigada..

Palavras-chave: Identidade docente. Formação de professores. Representações Sociais.

\footnotetext{
Doutora em Educação pela Universidade de Valencia (UV), Espanha. Professora do Departamento de Práticas Educacionais do Centro de Educação da Universidade Federal do Rio Grande do Norte (UFRN).

** Mestre em Educação pela Universidade do Rio Grande do Norte (UFRN). Professora da Secretaria de Estado da Educação e da Cultura do Rio Grande do Norte (SEEC/RN).
} 


\section{Representações e identidades: construções sociais}

Classificar, ordenar e organizar o mundo que nos rodeia é uma necessidade patente da humanidade. Explicar os fenômenos que se interpõem sobre a vida em sociedade é uma forma de dar sentido à própria existência. As representações sociais são construções que permitem significar e compreender a realidade na qual nos inserimos e orientar a conduta humana frente aos desafios da convivência coletiva. São definiçõos construídas de modo partilhado com o grupo a que pertencemos e, por esta medida, é impensável que possam ser produzidas de forma alienada da dinâmica social.

Nesse sentido, representar supera o caráter essencialmente restritivo de um processo mental individual sobre um objeto exterior e passa a incorporar uma conformação social não particular a um determinado indivíduo, mas imbuída de um sentido socializado, de um conhecimento compartilhado, de significados, formas e códigos compreensíveis e comuns a grupos de indivíduos dentro de uma mesma cultura. Dessa forma, as representações condicionam as relações que se estabelecem entre os indivíduos e a realidade, definindo suas práticas sociais e suas interações com os outros, sendo esta sua dupla função

Nenhuma mente está livre dos efeitos de condicionamentos anteriores que lhe são impostos por suas representações, linguagem ou cultura. Nós pensamos através de uma linguagem; nós organizamos nossos pensamentos, de acordo com um sistema que está condicionado, tanto por nossas representações, como por nossa cultura. Nós vemos apenas o que as convenções subjacentes nos permitem ver e nós permanecemos inconscientes dessas convenções. (MOSCOVICI, 2007, p. 35).

A necessidade de compreender o mundo para dominá-lo, ou seja, de criar representações sobre ele para torná-lo familiar e capaz de ser enfrentado é análoga ao processo de tomada de consciência do eu e da construção da própria identidade.

A potencialidade do aprender, e com esse aprendizado se desenvolver, aprimorando a vivência em sociedade, é inerente à humanidade. A própria socialização, o maior dos processos educativos, tem como base o ensinamento dos pais aos filhos, dos mais velhos e experientes à formação da juventude. É ao longo do processo de socialização, a que todos os humanos são submetidos, que se desenvolve a identidade de cada um: a forma independente de distinguir-se do outro.

Conforme afirma Giddens (2005, p. 43), "a identidade se relaciona ao conjunto de compreensões que as pessoas mantêm sobre quem elas são e sobre o que é significativo para elas". Desse conjunto se diferenciam as identidades pessoal e social. A identidade pessoal distingue os indivíduos e lhes confere sentido, sendo resultante das suas experiências com o mundo; já a identidade 

UFRN

social "refere-se às características que são atribuídas a um indivíduo pelos outros" (GIDDENS, 2005, p. 44). É nesta classificação que se enquadrariam o professor e a docência, enquanto uma identidade social:

Quando falamos identidade social aludimos aos sistemas de referências identitários que são atravessados por representações, práticas sociais, vinculadas a referentes materiais e simbólicos e ainda a expressões corporais, uma vez que se traduz no falar, sentar, gesticular de cada grupo. (LIRA, 2004, p. 78).

Embora analisadas de forma distinta, como salienta Giddens (2005), essas formas de identidade são intimamente relacionadas entre si, possuindo os indivíduos múltiplas identidades sociais, como por exemplo, a de professora, mãe e sindicalista. Dessa forma, é possível afirmar que as identidades sociais filiam os indivíduos uns aos outros, enquanto partícipes de um grupo, ao passo que a identidade pessoal os separa, enquanto indivíduos distintos, sendo ambas resultantes de negociações contínuas com o mundo exterior e com o outro.

Faz-se necessário ressaltar que essa multiplicidade de identidades se intensifica com a pluralidade de papéis sociais que assumem e com as dimensões pelas quais transitam os indivíduos, em especial na configuração das sociedades hodiernas. Mediatizados pelo mundo, produzem suas identidades, criando-as e recriando-as, em um processo contínuo, enquanto dura a existência e a troca de experiências.

Imprescindível nesses processos é a relação de alteridade que se estabelece para que se efetive a construção tanto da representação social quanto da constituição da identidade. Nesse sentido, a relação com o outro não está apenas no oposto, mas pareada com o eu; não apenas um espelho que reflete as distinções, mas, sobretudo, um duplo que intensifica as representações do grupo e reforça caracteres identitários.

Segundo Jodelet (2001), as representações sociais não apenas guiam as condutas humanas e os modos de interpretar e posicionar-se frente ao mundo, mas constroem uma visão consensual da realidade para os grupos, incidindo sobre outros processos, inclusive aqueles que definem as identidades: "Da mesma forma, elas intervêm em processos variados, tais como a difusão e a assimilação dos conhecimentos, o desenvolvimento individual e coletivo, a definição das identidades pessoais e sociais, a expressão dos grupos e as transformações sociais.” (JODELET, 2001, p. 22).

Se por identidade compreendemos algo próximo ao que Hall (2006) identifica como a concepção identitária do sujeito na modernidade tardia, ou seja, uma definição histórica, móvel, em deslocamento e em transformação, nos aproximamos ainda mais do diálogo com as representações 
sociais, uma vez que essas são concebidas para dar conta das transformações modernas, partindo de uma concepção de representação coletiva durkheimiana tomada como homogeneizante e de caráter estável (NÓBREGA, 2001).

Nesse sentido, tal como a noção de representação coletiva pareceu enveredar para uma concepção coesa e estática da realidade social, destoante do caráter heterogêneo da modernidade, "a identidade plenamente unificada, completa, segura e coerente é uma fantasia” (HALL, 2006, p. 13).

A Teoria das Representações Sociais (TRS), que em seus processos constitutivos elege a experiência, a memória, a história de grupos e indivíduos como elementos geradores de sua existência e tem por uma de suas funções assegurar as identidades, encontra sua origem com a publicação da tese de doutorado do psicólogo social romeno Serge Moscovici, em 1961, quando este, ao revitalizar o conceito de representações coletivas, alargando seu espectro de análise e compreensão da realidade social, cunhou a noção e a teoria das representações sociais, atualizando a preponderância da anterior, de caráter homogeneizante:

Para ele, as representações sociais não são nem homogêneas nem "partilhadas enquanto tais por toda a sociedade". E uma vez forjadas em condições socialmente desiguais, como resultado da divisão social do trabalho, as representações são, portanto, sociais, já que partilhadas, mas não homogêneas, porque partilhadas na heterogeneidade da desigualdade social. (NÓBREGA, 2001, p. 61).

É, portanto, no âmbito da irredutibilidade entre o social e o individual que Moscovici situa os estudos de representações sociais. Em suas palavras: "não existe sujeito sem sistema nem sistema sem sujeito. O papel das representações partilhadas é o de assegurar que sua coexistência é possível" (MOSCOVICI, 2011, p. 11).

[...] consideramos que não existe um corte dado entre o universo exterior e o universo do indivíduo (ou do grupo), que o sujeito e o objeto não são absolutamente heterogêneos em seu campo comum. O objeto está inscrito num contexto ativo, dinâmico, pois que é parcialmente concebido pela pessoa ou a coletividade como prolongamento de seu comportamento e só existe para eles enquanto função dos meios e dos métodos que permitem conhecê-lo. (MOSCOVICI, 1978, p. 48, grifo do autor).

Ao incrementar e atualizar o conceito de representações coletivas, as representações sociais se ocuparão do estudo de diversos fenômenos sociais em interface com distintas áreas do conhecimento, transformando-se elas próprias em objetos de estudo, como se pretende fazer nesta pesquisa, ao analisar-se as representações sociais do ser professor/a de Sociologia. 


\section{A Sociologia na educação básica: da intermitência à obrigatoriedade}

$\mathrm{Na}$ educação brasileira, intermitência é a palavra de ordem com que, geralmente, se define a historicidade da Sociologia enquanto componente curricular. A essa conjuntura poder-se-ia seguramente acrescentar que sua gênese está sob a égide de um certo obscurantismo, ou melhor, de uma multiplicidade de fatos. Moraes (2011) define o início da presença da Sociologia na educação brasileira nos pareceres de 1882-1883 de Rui Barbosa; em outro escrito, essa proposição ruibarbosiana retrocede a 1870, quando enseja a substituição da disciplina de Direito Natural pela Sociologia (MORAES; TOMAZI; GUIMARÃES, 2006). De qualquer maneira, a Sociologia vem traçando um caminho bastante diverso das outras disciplinas que atualmente integram o currículo da educação básica brasileira.

O ano de 1891 foi considerado como o início da história do ensino de Sociologia, por marcar a passagem de Benjamim Constant pelo Ministério da Instrução Pública durante o governo provisório de Deodoro da Fonseca, nos primeiros anos da República. Porém, a Reforma Benjamim Constant, que entre outras coisas tornava obrigatório o ensino da disciplina, não chegou a efetivar-se (MORAES, 2011).

Malgrado algumas iniciativas pontuais, a presença concreta da Sociologia no itinerário da educação básica só se efetivou realmente no século XX, quando "a Sociologia integrará os currículos, especialmente das escolas normais, embora aparecesse também nos cursos preparatórios [últimas séries do ensino secundário - que depois seria denominado de colegial e atualmente de ensino médio] ou superiores" (MORAES; TOMAZI; GUIMARÃES, 2006, p. 101, grifo dos autores). Nesse momento, a obrigatoriedade se instaura com o Decreto $n^{\circ} 16.782$ A, de 13 de janeiro de 1925, também chamado de Lei Rocha Vaz, que incluiu a Sociologia nos cursos ginasiais, atualmente correspondentes à segunda etapa do Ensino Fundamental. (MORAES, 2011; SILVA, T., 2007).

Em 1931 a Lei n ${ }^{\circ}$ 19.890, de 18 de abril, denominada Reforma Francisco Campos, mantém a Sociologia como disciplina obrigatória. De acordo com Silva (2007), esse é o momento em que a cadeira ganhará o grau superior das escolas secundárias. Essa condição perdurará até a Reforma Capanema, de 1942, que marcará o fim da obrigatoriedade do ensino de Sociologia na escola secundária. 
A partir desse momento, ressaltam Moraes, Tomazi e Guimarães (2006, p. 102), a intermitência da Sociologia no ensino secundário se intensifica,

Permanecendo no curso normal, às vezes como Sociologia Geral e quase sempre como Sociologia Educacional, mas no curso "clássico" ou no "científico" praticamente desaparece, visto que aí predominam disciplinas mais voltadas para a natureza dos cursos: Letras ou Ciências Naturais.

A primeira Lei de Diretrizes e Bases da Educação Nacional (LDBEN), Lei n ${ }^{\circ} 4.024$, de 20 de dezembro de 1961, não interferiu na condição da disciplina de Sociologia na educação básica e essa manteve-se como uma disciplina opcional entre as mais de uma centena de disciplinas existentes, permanecendo efetivamente excluída do currículo secundário (MORAES, 2011).

Desde que se constituíra institucionalmente enquanto disciplina, a Sociologia foi inserida e excluída dos currículos escolares ao sabor das reformas educacionais empreendidas em diversos momentos históricos e, de forma geral, essa conjuntura se manteve até o ano de 2008, quando foi sancionada a Lei $\mathrm{n}^{\mathrm{o}}$ 11.684, de 2 de junho de 2008, que alterou o Art. 36 da Lei $\mathrm{n}^{\circ}$ 9.394, de 20 de dezembro de 1996, atual LDBEN, instituindo a obrigatoriedade do ensino de Sociologia nos três anos que constituem o Ensino Médio.

Até antes da obrigatoriedade nacional do ensino de Sociologia sua atuação no nível médio estava restrita a alguns estados que, a partir da década de 1980, passaram a incluir a disciplina no currículo escolar a partir de uma legislação específica ou em suas constituições estaduais. Fato esse possibilitado pela Lei $\mathrm{n}^{\mathrm{o}} 7.044$, de 18 de outubro de 1982, que flexibilizava a obrigatoriedade do segundo grau profissionalizante, abrindo espaço para uma escola média de caráter formativo geral (MORAES, 2011). Nenhum estado da região Nordeste implementou ações nesse sentido. Apenas o Pará, no eixo norte-nordeste, tomou iniciativa de incluir a Sociologia no currículo a partir de reestruturações educacionais na década de 1980, conforme explicita Silva, I. (2007). Faz-se necessário ressaltar, entretanto, que essa inclusão pontual da disciplina não seguia nenhum critério geral, podendo ela figurar apenas em uma das séries do Ensino Médio ou ainda ficar a cargo da escola e do Projeto Político Pedagógico (PPP) a decisão de ofertá-la ou não à comunidade escolar:

O curso de Sociologia no Brasil voltou a ser ministrado na escola de $2^{\circ}$ grau e a ser definido como fundamental na construção do direito à cidadania. Mas o fato de ter sido mantida fora dos currículos escolares por mais de duas décadas, além de ter causado danos irreparáveis às gerações que frequentaram o $2^{\circ}$ grau nesse período, leva a que a reintrodução da Sociologia seja um tanto problemática. Um dos grandes desafios da política educacional de hoje é tornar a disciplina obrigatória na escola de $2^{\circ}$ grau, uma vez que, como optativa, não é ministrada em todas as escolas. Com isso, o número de aulas de Sociologia ainda é infinitamente menor que o das outras disciplinas, o que 
leva ser vista por muitos como um conjunto de aulas complementares para professores com outras habilitações que não Ciências Sociais. (MEKSENAS, 1990, p. 16).

Segundo Figueiredo (2004), no Rio Grande do Norte, em 2001, foi apresentado um projeto de lei ( $n^{\circ}$ 0461/01) pela Deputada Fátima Bezerra, o qual previa a obrigatoriedade do ensino de Filosofia e Sociologia nas escolas de Ensino Médio. Porém, aprovado no legislativo, tal projeto foi vetado em 2003, no executivo, pela então Governadora Vilma de Faria.

A imprecisão da LDBEN 9.394/1996, cuja redação do inciso III do $§ 1^{\text {o }}$ do Art. 36 explicita apenas que ao final do Ensino Médio o educando deve obter o "domínio dos conhecimentos de Filosofia e de Sociologia necessários ao exercício da cidadania” (LDBEN, 1996, p. 14), deu margem a uma interpretação que permitia ao ensino de Sociologia figurar na parte diversificada do currículo, ou seja, com seus saberes diluídos em outras áreas de conhecimento ou compondo projetos de temáticas transversais, facultando, nesse sentido, a oferta da disciplina pelas escolas.

Essa situação permaneceu, de forma geral, até 2 de junho de 2008, quando a Lei $\mathrm{n}^{\mathrm{o}} 11.684$ tornou obrigatório o ensino de Sociologia e Filosofia no Ensino Médio brasileiro. A obrigatoriedade fez surgir diversos desafios e preocupações com a reinclusão da Sociologia na escola. Intensificou o surgimento de diversas pesquisas acerca das problemáticas que envolvem o ensino dessa disciplina, sua presença na escola e a formação dos professores que a lecionam.

Entretanto, de acordo com Silva (2007, p. 417), a instabilidade na legislação a respeito do ensino de Sociologia “interfere na formação de professores, uma vez que o espaço de trabalho como professor de sociologia não está consolidado". Passados quase seis anos da obrigatoriedade, esse espaço ainda carece de consolidação, pois a situação descrita por Meksenas (1990) no final da década de 1980 a respeito do número de aulas e do fato de a disciplina ser encarada como um conjunto de aulas complementares para professores não habilitados permanece de uma forma geral e em especial na realidade educacional do Rio Grande do Norte.

Essa descontinuidade da disciplina de Sociologia gerou efeitos intensos na identidade tanto dos sujeitos ora atuantes como professores dessa disciplina, quanto dos futuros professores, os licenciandos. Ou seja, extensivamente, esses caracteres de fragmentação e não linearidade são herdados pelo grupo de sujeitos que formam atualmente os docentes de Sociologia.

O objeto ou situação que se pretende conhecer, a partir da representação social, necessita ter relevância ao grupo em questão, ser pensado e compartilhado coletivamente. Ao se remeter à disciplina de Sociologia, ao seu ensino ou mesmo àqueles que a lecionam, é possível identificar um momento de 
especial transição para que esse objeto possa ser construído em termos de uma representação social. Esse momento se localiza nos instantes que precedem a obrigatoriedade da disciplina, no qual as questões, preocupações e desafios decorrentes desse fato passam a figurar no cotidiano acadêmico e escolar das instituições formadoras, dos licenciandos e das escolas. A obrigatoriedade do ensino de Sociologia e, antes disso, as batalhas travadas por sua reinserção trouxeram à tona uma série de pesquisas, levantamentos e estudos que estão cumprindo uma função primordial para a construção de uma identidade da disciplina e para os atores que a ela estão relacionados, por meio do resgate da memória e trajetória da Sociologia na escola básica, embora, como será explicitado posteriormente, o alcance das discussões dessa problemática ainda não abarquem a totalidade dos licenciandos e concentrem-se em momentos tardios de seu percurso formativo.

\section{Percurso metodológico - sujeitos, procedimentos e instrumentos de pesquisa}

Disseminada sob a égide de um campo em aberto, a teoria das representações sociais construída por Moscovici fomentou o desenvolvimento de diversas outras microteorias, abordagens complementares à grande teoria que auxiliaram na consolidação do campo e, especialmente, das metodologias específicas ao seu intento. A abordagem estrutural ou Teoria do Núcleo Central (TNC) compõe esse rol de estudos que desdobram e enriquecem a grande teoria e parte da tese de doutoramento de Jean-Claude Abric, defendida em 1976, a respeito da organização interna das representações sociais (LIMA, 2013). A abordagem estrutural busca estudar as representações sociais a partir da noção de que essas constituem sistemas estruturados em torno de dois subsistemas distintos, porém interdependentes: um sistema central e um sistema periférico. Segundo Sá (1998), essa proposição organizacional do conteúdo de uma representação com características e funções distintas é a principal contribuição da abordagem estrutural à teoria das representações sociais.

A concepção do núcleo central encontra sua gênese mais tardia na noção de núcleo figurativo que acompanha o processo de objetivação presente na constituição de uma representação social.

Em linhas gerais, o núcleo figurativo é uma estrutura imagética em que se articulam, de uma forma mais concreta ou visualizável, os elementos do objeto de representação que tenham sido selecionados pelos indivíduos ou grupos em função de critérios culturais e normativos. (SÁ, 1996, p. 65).

Nesse sentido, o núcleo central guarda em si duas funções essenciais: a de gerar sentido à representação, bem como aos outros elementos da estrutura periférica; e a de organizar a relação entre 
os vários elementos que compõem a representação, dando estabilidade aos caracteres mais ressaltados pelo grupo. É a existência desse componente central que determina como o objeto é representado e, por sua vez, orienta o comportamento daqueles enredados com a representação.

Vários métodos de levantamento do núcleo central foram construídos a partir da disseminação da abordagem estrutural junto aos pesquisadores das representações sociais. Uma das grandes questões a ser resolvida por esses métodos é a de não apenas realizar um levantamento quantitativo dos possíveis elementos formadores do núcleo central, mas conseguir dar conta da significância desses elementos e suas inter-relações, ou seja, exprimir o caráter social das representações. A dificuldade não é despropositada, dado o espaço interseccional em que se localizam as representações, entre o individual e o coletivo. Nesse sentido, os métodos utilizados para seu levantamento necessitam dar conta do caráter individual difusor das representações, sobretudo enfatizar a comunicação intersubjetiva dos indivíduos e grupos, destacando o caráter coletivo enquanto processo gerador dessas representações.

A Técnica de Associação Livre de Palavras (TALP) se apresenta como um desses métodos de levantamento e "consiste em se pedir aos sujeitos que, a partir de um termo indutor [...] apresentado pelo pesquisador, digam as palavras ou expressões que lhe tenham vindo imediatamente à lembrança" (SÁ, 1996, p.115). Esse recurso, que de acordo com Melo (2009) possibilita uma incursão no universo linguístico e simbólico dos sujeitos, é "bastante utilizado na apreensão das representações sociais por ser de fácil aplicação e dirimir possíveis interferências dos sujeitos quanto à manipulação dos dados” (MELO; DOMINGOS SOBRINHO, 2005, p. 111). A TALP consiste, então, em, a partir de um termo indutor, estimular o pesquisado a apontar palavras que se relacionem ao estímulo dado.

$\mathrm{O}$ artigo que ora se apresenta, constitui-se em um excerto de uma pesquisa maior que resultou numa dissertação de mestrado recentemente apresentada, cujos sujeitos eram os licenciandos do curso de Ciências Sociais da UFRN que estavam ingressando no curso durante os primeiros semestres letivos dos anos de 2013 e 2014, além dos licenciandos estagiários que estavam matriculados nas atividades de estágio supervisionado durante esses semestres. O objeto representacional investigado foi a docência em Sociologia, com foco na representação da identidade docente por parte dos licenciandos, e o termo indutor utilizado na TALP foi - Ser professor(a) de Sociologia é....

No total foram aplicados 29 formulários com a técnica de associação livre de palavras aos licenciandos ingressantes, e 44 formulários aos estagiários matriculados nas atividades de Estágio Supervisionado de Formação de Professores, nas duas etapas finais, considerando que o referido estágio se constitui de quatro etapas. Conforme o estabelecido na Portaria no 09/2008, de 10 de junho 
de 2008, que institui o Regulamento das Atividades Especiais Coletivas Estágios Supervisionados de Formação de Professores nos Cursos de Licenciatura da Universidade Federal do Rio Grande do Norte, os estágios supervisionados para a formação de professores constituem atividades obrigatórias a serem desenvolvidas nos quatro últimos semestres de curso. Cada uma dessas quatro atividades é denominada, em ordem crescente, de Estágio Supervisionado de Formação de Professores I, Estágio Supervisionado de Formação de Professores II, Estágio Supervisionado de Formação de Professores para o Ensino Fundamental e Estágio Supervisionado de Formação de Professores para o Ensino Médio. Nas licenciaturas que formam professores apenas para o Ensino Médio, como é o caso da licenciatura em Ciências Sociais, o Estágio Supervisionado de Formação de Professores para o Ensino Fundamental é substituído pelo componente curricular denominado Estágio Supervisionado de Formação de Professores III. Nesse sentido, a escolha pelas últimas duas etapas do estágio supervisionado se deu em razão de, nessa fase, os licenciandos se encontrarem em contato direto com a docência, seja auxiliando o professor da escola na condução das aulas e na preparação do material didático, seja exercendo a regência da sala de aula. Dessa forma, foi possível analisar as representações dos licenciandos comparando-as a partir de duas etapas extremas da formação desses sujeitos.

A TALP foi aplicada às turmas investigadas em sala de aula, após a anuência do professor regente. Nesse momento, também foram observadas as aulas em que seriam aplicados os instrumentos, bem como procedeu-se a conversas informais com os licenciandos a respeito da problemática investigada. Além disso, faz-se necessário ressaltar que todos os sujeitos implicados no levantamento dos dados necessários a esta pesquisa se dispuseram voluntariamente a participar do estudo, e suas participações foram autorizadas mediante a assinatura do termo de consentimento livre e esclarecido.

Aqui, apresentaremos exclusivamente a comparação entre a estruturação dos núcleos centrais que formam a representação social da docência em Sociologia para esses dois grupos e suas intersecções com a formação a que são submetidos e com a realidade do ensino de Sociologia no estado do Rio Grande do Norte.

\section{Núcleos centrais das representações sociais do ser professor/a de Sociologia}

Para analisar os dados coletados pela TALP, utilizou-se o software Ensemble des Programmes Permetant l'Analyse des Evocations (EVOC), o qual mapeou as evocações apontadas pelos investigados durante a aplicação do instrumento para formação dos Núcleos Centrais das representações sociais analisadas nesta pesquisa. Fez-se uso também da categorização proposta por 

UFRN

Bardin (2011) para analisar e classificar o conteúdo das justificativas informadas pelos licenciandos após a hierarquização das palavras evocadas.

Foram evocadas 87 palavras pelos licenciandos ingressantes, sendo 61 palavras diferentes, e 132 palavras pelos licenciandos estagiários, sendo 82 palavras diferentes. Excluíram-se as evocações mencionadas apenas uma vez. Dessa forma, para a composição do Núcleo Central (NC) das representações sociais, considerou-se o ponto de corte 2, ou seja, limitamos a análise do EVOC àquelas palavras mencionadas por, pelo menos, dois entrevistados. Nesse sentido, foi realizada também uma assepsia nos termos evocados, e agrupados semanticamente os elementos que se assemelhavam. Para tanto, levou-se em conta a justificativa apresentada por cada sujeito para as palavras evocadas. Os elementos que possuíam sentidos aproximados, mas que continham justificativas distintas, não foram agrupados. Como, por exemplo, EDUCADOR e EDUCAÇÃO.

Conforme a Figura 1, que apresenta o núcleo central das representações sociais dos sujeitos que formam o subgrupo dos licenciandos ingressantes, a representação que estes possuem acerca do ser professor(a) de Sociologia se constrói sobre o elemento evocativo APRENDER.

A estrutura, além de apresentar as palavras que formam as esferas representacionais, informa também as variáveis utilizadas para a construção do NC. Além do ponto de corte anteriormente mencionado, a estrutura foi construída tendo por base a frequência 4 e a OME 2.00. Ou seja, as palavras foram dispostas considerando o NC como os elementos que foram evocados 4 ou mais vezes e nas primeiras hierarquizações $(\mathrm{f}>=4 / \mathrm{OME}<2)$; a primeira esfera intermediária, considerando as palavras 4 ou mais vezes evocadas, mque estavam hierarquizadas numa posição maior ou igual a segunda colocação ( $\mathrm{f}>=4 / \mathrm{OME}>=2$ ); a segunda esfera intermediária, com os elementos mencionados menos de 4 vezes, mas que estavam hierarquizados nas primeiras colocações ( $<<4 / \mathrm{OME}<2)$; e, finalmente, na periferia, tem-se os elementos mencionados em uma frequência menor do que 4 e com ordem de importância entre o segundo e terceiro lugares ( $\mathrm{f}<4 / \mathrm{OME}>=2)$.

Visando a uma comparação mais fidedigna dos dados, esses valores foram utilizados tanto para a estruturação do NC dos licenciandos ingressantes quanto dos estagiários: 
Figura 1 - Estrutura representacional dos licenciandos ingressantes

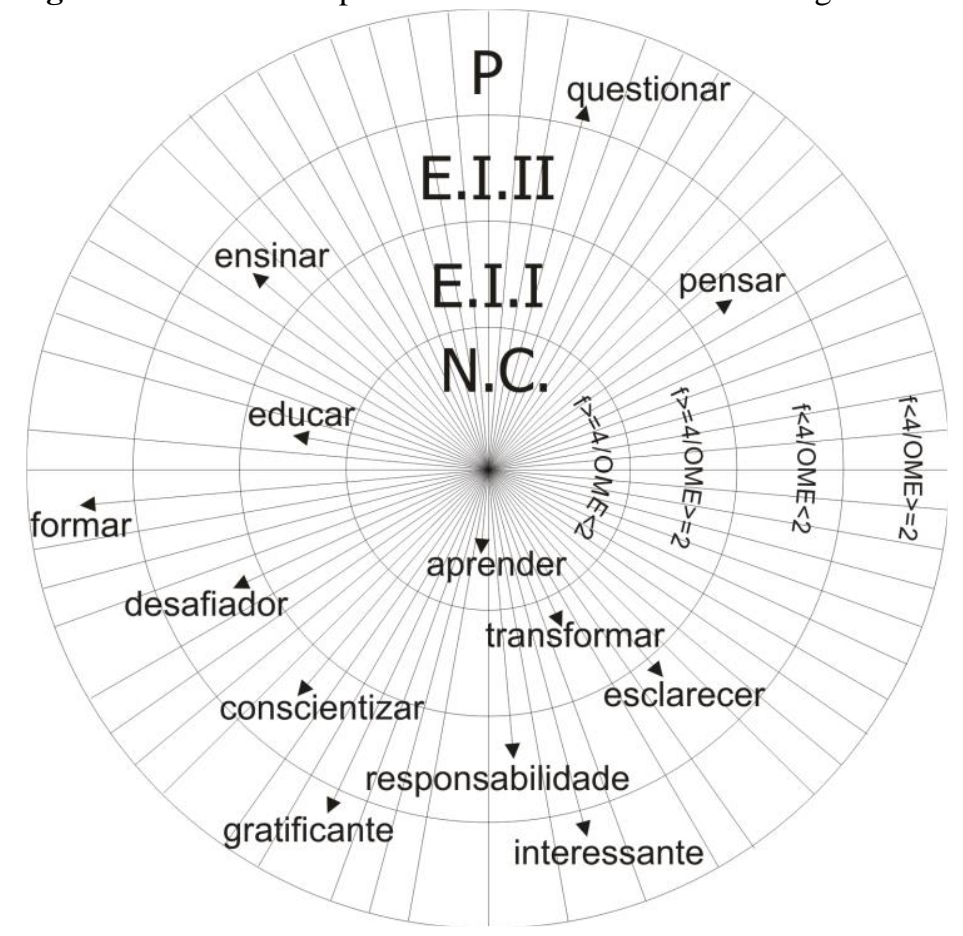

Fonte: Elaborado pelas autoras (2016).

A partir da Figura 1, percebe-se que o Núcleo Central está consubstanciado no componente representacional: APRENDER. Ou seja, este se traduz no elemento mais fortemente arraigado e amplamente difundido por tais entrevistados, pois diz respeito ao que é considerado, pelos licenciandos, como o contraponto inseparável do ato de ensinar, a aprendizagem que o profissional apreende em sua prática cotidiana. Nessa direção, apresentamos, a seguir, algumas falas dos sujeitos pesquisados, que ilustram essa perspectiva:

Antes de qualquer coisa, ao ensinar também aprendemos. (Id. 1).

Aprendemos com os alunos e com todos os inter-relacionamentos provenientes da profissão. (Id. 2).

Aprender, pois todo professor aprende com seus alunos e com o próprio dia a dia. (Id. 15).

Para mim, ser professora de sociologia é constante aprendizado. (Id. 18).

Evidentemente, essa relação entre ensino e aprendizagem não é exclusiva do ensino de Sociologia e pouco revela acerca da representação de uma possível identidade docente para esses discentes. 

UFRN

Ainda que contabilizado na evocação ALUNO, e não em APRENDER, a justificativa dada pelo sujeito ingressante $n^{\circ} 5$ é análoga às justificativas acima transcritas, pois se relaciona também ao aprendizado prático que o enfrentamento com a sala de aula pode oportunizar ao profissional docente: "Ser professor de sociologia é ser aluno, pois ao entrarmos em uma sala de aula estamos aprendendo o tempo todo." (Id. 5).

Repercute nas falas dos discentes também uma relação entre docência e prática. Sobressai-se nas falas desses sujeitos que o ser professor constitui-se, efetivamente, na prática de sala de aula. Dessa forma, a evidente relação entre docência e prática pode revelar um vir a ser contínuo, no sentido de que esses licenciandos ainda não se sentem professores. Entretanto, semanticamente, os licenciandos ingressantes se põem na situação de sujeitos docentes. Além disso, em função da obrigatoriedade, semelhante ao que ocorre em outras licenciaturas, alguns desses estudantes, ainda que o número seja bastante reduzido, já vivenciaram anteriormente ou desempenhavam, no momento da pesquisa, atividades docentes. Portanto, é possível inferir dessas colocações uma generalidade a respeito da associação entre o ato de ensinar e o ato de aprender. Uma representação que pode estar atrelada às memórias discentes e à vivência escolar, a um discurso difundido pelo senso comum. Uma representação que poderia ser construída por qualquer grupo de licenciandos, uma vez que não revela nada específico sobre o lugar de onde esses sujeitos falam. As generalizações das justificativas representam uma associação com a docência, mas não com a docência em Sociologia.

Contraditória também é a relação que esses sujeitos estabelecem com a prática docente, pois em outro momento da pesquisa, o principal elemento destacado foi o distanciamento entre a sala de aula e os professores em formação, o distanciamento da prática. Nesse sentido, se os licenciandos representam a docência como um aprendizado prático, nada mais coerente do que inserir essa dinâmica e essas experiências o quanto antes em sua formação.

Nessa linha, a relação teoria e prática é tema basilar nos debates sobre formação de professores e sua articulação se constitui também em um dos grandes desafios da formação inicial. Tardif (2000) credita essa desarticulação ao modelo aplicacionista, que subverte os cursos de formação de professores. Para esse autor, a dinâmica dessa formação consiste em os alunos assistirem aulas organizadas conforme disciplinas e ao final aplicarem esses conhecimentos em seus estágios. Nesse momento, descobrem que tais conhecimentos não se aplicam à ação cotidiana, revelando uma formação fragmentada e descolada da realidade da atuação docente. 
Tal situação se sobressai quando a última justificativa acerca do elemento nuclear APRENDER é trazida à tona. Para o licenciando ingressante, tal elemento se relaciona à formação do professor: "Primeiro temos o dever de aprender a lecionar" (Id. 12). E como se aprender a ser professor?

Pimenta (1997) elenca três tipos de saberes que conformariam os saberes da docência, a saber: a experiência, o conhecimento e os saberes pedagógicos. A experiência não diz respeito apenas à prática docente, mas também, especialmente no caso dos licenciandos, às vivências socialmente acumuladas durante suas trajetórias escolares e no contato com as construções representacionais acerca dos professores fomentadas pelos meios de comunicações, pelas suas próprias famílias e por outras instituições sociais; o conhecimento inclui, obviamente, os saberes específicos da área na qual o licenciando está sendo formado - no caso dos licenciandos aqui investigados, as Ciências Sociais mas, sobretudo, o processo de "mediação entre a sociedade da informação e os alunos" (PIMENTA, 1997, p. 4).

Por último, a terceira categoria de saberes inclui os saberes pedagógicos, como o conhecimento da prática social dos docentes, e "revela que de certa maneira há um reconhecimento de que para saber ensinar não bastam a experiência e os conhecimentos específicos, mas se fazem necessários os saberes pedagógicos e didáticos” (PIMENTA, 1997, p. 5).

Dessa forma, tem-se uma tríade inter-relacional de saberes que conformariam o ser professor e, de forma relacional, sua identidade docente: as experiências anteriores, o conhecimento específico e a didática. De modo que, se numa formação inicial de professores o conhecimento específico não estiver atrelado a uma mediação pedagógica que torne aqueles saberes apropriados ao público da educação básica, se não se atrelar à experiência e à prática social dos docentes, dificilmente esse curso cumprirá sua função de formar professores.

As consequências para a formação dos professores são que a formação inicial só pode se dar a partir da aquisição da experiência dos formados (ou seja, tomar a prática existente como referência para a formação) e refletir-se nela. $O$ futuro profissional não pode constituir seu saber-fazer, senão a partir de seu próprio fazer. Não é senão sobre essa base que o saber, enquanto elaboração teórica, se constitui (PIMENTA, 1997, p. 6, grifos do autor).

Elevar a prática docente ao grau de elemento imprescindível na constituição da identidade docente se localiza aqui como elemento primordial desta pesquisa. Se a experiência com a Sociologia no Ensino Médio, e com os professores que a lecionavam, se apresentou como determinante para a eleição da Licenciatura em Ciências Sociais pelos ingressantes, o relacionamento com a prática docente daqueles que, atualmente formados, se encarregam de lecionar e lidar com as pesquisas no âmbito do 

UFRN

ensino de Sociologia se torna de fundamental importância para a formação do futuro professor (inclusive porque esse contato aprofundado durante a formação inicial poderia modificar as pretensões futuras desses licenciandos após a conclusão da licenciatura) e para a constituição de caracteres identitários que se associem de forma a possibilitar a identificação com a docência. Conforme afirma Tardif (2000, p. 12), “é preciso, portanto, que a pesquisa universitária se apoie nos saberes dos professores a fim de compor um repertório de conhecimentos para a formação de professores".

Nesse sentido, se torna primordial para a constituição da representação social que o grupo faz do(a) professor(a) de Sociologia o contato com a memória desse grupo e suas práticas. "Memória que, analisada e refletida, contribuirá tanto à elaboração teórica, quanto ao revigoramento e o engendrar de novas práticas.” (PIMENTA, 1997, p. 6-7). Ou seja, ao refletir-se sobre o que se fez e apoderar-se da história e das experiências dentro do ensino e da pesquisa sobre o ensino de Sociologia, traça-se um caminho não só para a construção de uma identidade desses futuros professores com a prática docente da Sociologia, mas para a própria consolidação da disciplina no Ensino Médio e dos cursos de formação de professores no Ensino Superior.

Exposto o Núcleo Central da representação social sobre ser professor(a) de Sociologia expressa pelos licenciandos ingressantes em Ciências Sociais da UFRN, apresentamos, a seguir, a Figura 2, que demonstra a estrutura representacional dos licenciandos estagiários:

Figura 2 - Estrutura representacional dos licenciandos estagiários

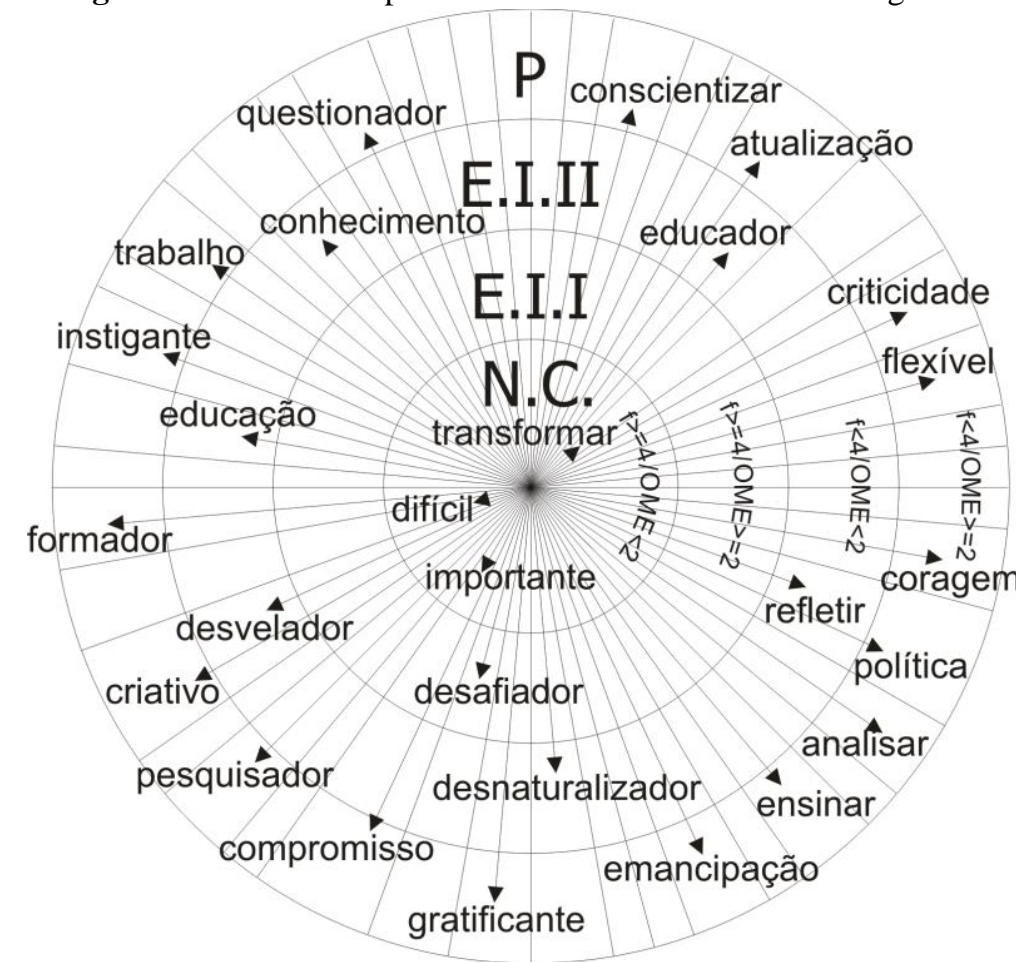

PERSPECTIVA, Florianópolis, v. 35, n. 1, p. 49-72, jan./mar. 2017

http://www.perspectiva.ufsc.br 
Fonte: Elaborado pelas autoras (2016).

A Técnica de Associação Livre de Palavras foi aplicada apenas às duas últimas etapas do estágio supervisionado, nas quais os licenciandos já possuem contato direto com a prática docente.

Dessa forma, a comparação com o núcleo central da representação social construído pelas representações dos licenciandos ingressantes se torna mais evidenciada, pois tem elementos adquiridos nos primeiros e últimos períodos do curso de formação de professores.

O núcleo central da representação social dos licenciandos estagiários é constituído por três elementos, diferente daquele referente aos ingressantes que apresenta um único elemento. Segundo Abric (1998, p. 31),

Toda modificação no núcleo central provoca uma transformação completa da representação. Nós afirmamos, então, que é a identificação do núcleo central que permite o estudo comparativo das representações. Para que duas representações sejam diferentes, elas devem ser organizadas em torno de dois núcleos centrais diferentes. A simples identificação do conteúdo de uma representação não basta para o seu reconhecimento e especificação. A organização deste conteúdo é essencial: duas representações definidas por um mesmo conteúdo podem ser radicalmente diferentes, caso a organização destes elementos, portanto sua centralidade, seja diferente.

Dessa forma, além de se configurarem representações sociais distintas sobre o mesmo fenômeno, construídas a partir de grupos similares, é notório que o elemento que perfaz o núcleo central para os licenciandos ingressantes, ou seja, aquele sentido representacional mais arraigado ao grupo e mais intensamente compartilhado (aprender), nem ao menos figura no desenho representacional dos licenciandos estagiários.

Tal fato evidencia que a formação a que são submetidos os licenciandos age de forma determinante sobre suas representações acerca da identidade docente do(a) professor(a) de Sociologia. Agrega-se também a esse quadro o fato de que os elementos que se unem para formar o núcleo central da representação social para os licenciandos estagiários são bem mais direcionados e menos genéricos do que os sentidos atribuídos à primeira conformação representacional. Diante das disparidades apresentadas entre os dois núcleos e ressaltando que as atividades referentes aos estágios supervisionados encontram-se localizadas nas últimas etapas da estrutura curricular da licenciatura, percebe-se a parca relação com a docência que as disciplinas propedêuticas estabelecem com a prática. Desse modo, o determinismo da modificação representacional encontra-se situado nas atividades dos estágios supervisionados. 

UFRN

Os elementos TRANSFORMAR, DIFÍCIL e IMPORTANTE que compõem o núcleo central, evidenciam mais fortemente caracteres que podem ser indicadores de uma identidade docente do(a) professor(a) de Sociologia, pois interligam-se entre si de forma mais imbricada para demonstrar que a importância está na possibilidade de transformação que o conhecimento sociológico pode fomentar nos alunos, permitindo-lhes vislumbrar suas realidades de outras perspectivas, mas que as dificuldades inerentes à docência, bem como à própria conjuntura estrutural enfrentada pela Sociologia, no Rio Grande do Norte, atuam como barreiras desafiadoras para se atingir essa transformação almejada, como verificamos nos discursos a seguir.

Primeiro, acho importante para a construção crítica da sociedade. (Id. 12).

Difícil está ligado às enormes dificuldades enfrentadas pela profissão (baixos salários, dificuldades físicas encontradas nas escolas - questões estruturais) e pouca possibilidade real de tratamento interdisciplinar na rede pública de forma geral. (Id. 4).

Difícil: o tempo cedido pelas escolas e a importância que dão à matéria ainda é muito insignificante (questão de valor). (Id. 34).

Temos o papel de transformar mentalidades, de sujeitos oprimidos para autônomos; opressor em solidário. (Id. 32).

O professor não pode deixar de formar para que os alunos transformem suas existências criticamente. (Id. 42).

A questão da transformação como centralidade no papel do professor se apresenta nesse momento da formação, embora posta com algumas ressalvas, uma vez que é relativizada pelos desafios e dificuldades inerentes à educação básica e ao professorado no Brasil. Destacamos que essas questões, próprias do fazer docente e da condição política que ocupa o magistério brasileiro, estão circunscritas às representações formadas pelos licenciandos estagiários, fortalecendo a perspectiva anteriormente aludida de que, embora se coloquem discursivamente na condição de docentes, os licenciandos ingressantes ainda representam a docência, a escola e o ensino de Sociologia a partir de sua escolarização, uma vez que as características e preocupações próprias do cotidiano docente do ensino de Sociologia estão ausentes naquela representação.

O estágio como campo de conhecimento e eixo curricular central nos cursos de formação de professores possibilita que sejam trabalhados aspectos indispensáveis à construção da identidade, dos saberes e das posturas específicas ao exercício profissional docente. (PIMENTA; LIMA, 2012, p. 61). 
Pimenta e Lima (2012) situam o estágio como um momento especial à construção da identidade docente. Entretanto, esse fomento não pode depender exclusivamente desses momentos, que só ocorrerão nos últimos períodos da formação. Ressalte-se uma vez mais que a preponderância de se relacionar teoria e prática em todos os componentes curriculares da formação do professor é imprescindível para agregar no licenciando caracteres que lhe permitam construir uma relação de pertencimento e identidade com a docência. Para Tardif (2000, p. 19), "Os conhecimentos proposicionais sobre o ensino baseados na lógica disciplinar, conhecimentos esses veiculados durante a formação, constituem, portanto, uma falsa representação dos saberes dos profissionais a respeito de sua prática."

Portanto, conforme o autor (2000), mais do que simplesmente agregar uma dimensão prática às disciplinas, é fundamental que esse fazer esteja relacionado à prática docente, sob pena de falsear um imaginário nesses licenciandos sobre a realidade de suas futuras atuações profissionais. Seja em ambientes escolares ou não escolares, o licenciando em Ciências Sociais necessita estar consciente de que sua formação está voltada à docência e perseguir essa identidade por meio dos saberes docentes que devem ser desenvolvidos durante o curso.

Para Tardif (2000), é prerrogativa do professor dominar diversos saberes, os quais são adquiridos, em sua maioria, na formação inicial. São eles: saberes profissionais - conjunto de saberes transmitidos pelas instituições de formação de professores (psicologia, sociologia, filosofia, etc.); saberes das disciplinas - ofertados e selecionados pela instituição universitária, nas diversas disciplinas oferecidas durante o curso; saberes curriculares - correspondem aos discursos, objetivos, conteúdos e métodos com os quais a instituição escolar categoriza e apresenta os saberes sociais selecionados por ela, a partir da cultura erudita, sob a forma de programas escolares que os professores devem aprender e aplicar; saberes da experiência - saberes específicos do trabalho cotidiano e no conhecimento de seu meio. Eles incorporam-se à vivência individual e coletiva sob a forma de habilidades, de saber fazer e de saber ser.

Embora apenas este último pressuponha uma experiência prática, mesmo assim ela pode ser fomentada a partir de uma estruturação curricular que permita ao discente envolver-se com o cotidiano escolar desde o início do curso.

A identidade do professor é construída ao longo de sua trajetória como profissional do magistério. No entanto, é no processo de sua formação que são consolidadas as opções e intenções da profissão que o curso se propõe legitimar (PIMENTA; LIMA, 2012, p. 62). 

UFRN

Diante da centralidade da relação teoria e prática, bem como das discussões envolvendo a docência nos momentos do estágio supervisionado, percebe-se que essa não será uma barreira simples de ser transposta, embora, nesse sentido, ressalte Gatti (2010, p. 1357) que essa problemática se replica por outras licenciaturas, cujo o tempo de presença na educação básica é bem maior do que o da Sociologia:

Verifica-se nas licenciaturas dos professores especialistas a prevalência da histórica ideia de oferecimento de formação com foco na área disciplinar específica, com pequeno espaço para a formação pedagógica. Adentramos o século XXI em uma condição de formação de professores nas áreas disciplinares em que, mesmo com as orientações mais integradoras quanto à relação "formação disciplinar/formação para a docência", na prática ainda se verifica a prevalência do modelo consagrado no início do século XX para essas licenciaturas.

Além disso, em virtude de a representação dos licenciandos estagiários se encontrar intrinsecamente relacionada à transformação, seja essa advinda dos sentidos que o conteúdo sociológico pode despertar ou mesmo do que o professor é capaz de realizar com esse conteúdo, se faz necessário que as disciplinas específicas da formação, além de privilegiarem a transposição didática, problematizem qual o papel da Sociologia no Ensino Médio, sob pena de terem futuros professores frustrados por não verem concretizada essa missão revolucionária, que se está construindo para ombros que talvez não estejam preparados para sustentá-la.

Em linhas gerais, percebemos que para os ingressantes do curso de licenciatura em Ciências Sociais da UFRN existe uma representação social sobre ser professo(a) de Sociologia, construída com base nos modelos de escolarização experienciados ao longo de suas vidas como estudantes e baseado no processo de aprender. Entretanto, para os estagiários, ser professor(a) de Sociologia envolve uma dimensão idiossincrática da sociologia, a qual gravita em torno de um pretenso poder de transformação da realidade. Entretanto, percebem esse papel transformador como algo importante, porém difícil em função da conjuntura que envolve a problemática subjacente ao ensino de Sociologia, decorrente do seu pouco tempo de inserção no currículo, do pouco espaço que obtém frente às demais disciplinas e, efetivamente, diante da complexidade inerente à carreira docente de modo geral.

\section{Considerações Finais}

Após a obrigatoriedade do ensino de Sociologia nos currículos do Ensino Médio, as professoras e professores que ministram essa disciplina venceram muitas barreiras. O que não significa que a 
consolidação desse componente curricular na educação básica brasileira esteja assegurada. A legitimidade da Sociologia e sua presença na escola são uma batalha cotidiana de todas e todos que se relacionam com a esfera educativa. Entretanto, é possível afirmar, nesse momento, que já estamos colhendo alguns frutos dessa batalha.

Embora as percepções dos licenciandos ingressantes sejam generalistas, o fato de terem tido contato com a disciplina e com os professores durante o Ensino Médio trouxe elementos e experiências que estão se agregando na formação de suas representações. Essas generalizações se tornam mais evidentes quando comparados os dois núcleos centrais anteriormente apresentados: o primeiro, formado por uma representação de discentes ingressantes na licenciatura, e o seguinte, construído a partir da representação de licenciandos concluintes (estagiários).

Tanto a primeira estrutura representacional quanto a segunda apresentam elementos que impulsionam discussões sobre a formação de professores em Ciências Sociais. A primeira sugere um patente distanciamento das discussões sobre a docência e da relação entre teoria e prática, em especial nos momentos de formação das disciplinas específicas. A segunda apresenta um sentido calcado na noção de transformação capaz de ser propiciada pela disciplina e pelo papel de agente a ser desempenhado pelos docentes na realidade dos alunos. Alguns licenciandos estagiários circunscrevem tais mudanças às posturas críticas dos alunos frente à organização social. Outros vão mais além e fazem alusão a uma "mudança em grande escala", evidenciando suas crenças na "transformação social".

Essa representação da identidade docente se confunde com a própria representação da disciplina e dos sentidos que os licenciandos constroem para ela. Dessa maneira, não se apresenta de forma clara uma representação sobre ser professora e professor de Sociologia, mas das pretensas potencialidades que o saber sociológico seria capaz de engendrar na realidade cotidiana. Quiçá esse resultado se dê em função da parca relação teoria-prática e do patente distanciamento desses licenciandos da escola básica, pois, com raríssimas exceções, o contato com a escola está restrito aos últimos períodos do curso, nas atividades de estágio supervisionado de formação de professores.

Nesse sentido, embora em certa medida seja lugar-comum alertar para o distanciamento entre teoria e prática, entre academia e escola básica, para se ter uma identidade que não seja apenas prescritiva, que não vislumbre apenas um “tipo ideal” de professor, é necessário trazer a escola para o itinerário formativo desses licenciandos, inserindo-os desde os primeiros momentos de sua formação inicial em seu campo de atuação, em especial no que se refere à formação específica.

Dessa forma, não se pretende aqui associar os dilemas do ensino de Sociologia exclusivamente às problemáticas em torno da formação inicial do professor de Sociologia. É sabido que tais questões 

UFRN

passam também pela precarização das condições de trabalho que vivencia hoje o magistério brasileiro. Em especial, no caso do ensino de Sociologia, tem-se também a questão primordial da quantidade de carga horária dessa disciplina e da permanência de professores não habilitados conduzindo seu ensino, especialmente na conjuntura educacional vivenciada pelo estado do Rio Grande do Norte.

Diante desses desafios, a academia necessita eleger a função de formar professores para a educação básica como uma de suas missões mais importantes. E, nesse sentido, é imprescindível voltar suas atenções para a (re)estruturação das licenciaturas. A licenciatura em Ciências Sociais da UFRN precisa rever as concepções políticas e pedagógicas subjacentes ao perfil de formação pretendido, no sentido de aproximar os licenciandos da escola e da docência em Sociologia. Faz-se necessário ainda voltar os olhos para as experiências exitosas de outras Instituições de Ensino Superior (IES) que ofertam a licenciatura e refletir sobre o lugar ocupado pela prática docente dentro dessas matrizes curriculares. Mais ainda, é preciso firmar parcerias que transformem professores formadores, licenciandos e professores da educação básica em parceiros nas investigações sobre as problemáticas e desafios inerentes ao ensino de Sociologia, pois este parece ser um caminho viável para a consolidação da disciplina de Sociologia na educação básica e, principalmente, para a aproximação dos licenciandos da escola e o fortalecimento de caracteres identitários docentes.

Se não há uma identidade clara sobre como os licenciandos representam a docência em Sociologia é preciso refletir em que medida esses caracteres estão sendo fomentados durante o processo de formação inicial. Se essa representação se confunde com um sentido interventivo da Sociologia, precisa-se voltar e questionar o perfil de Cientista Social que está sendo formado e a perspectiva docente que orienta as concepções pedagógicas da licenciatura.

\section{REFERÊNCIAS}

ABRIC, Jean-Claude. A abordagem estrutural das representações sociais. In: PAREDES MOREIRA, Antônia Silva; OLIVEIRA, Denize Cristina de. (Orgs.). Estudos interdisciplinares de representação social. Goiânia: AB, 1998.

BARDIN, Laurence. Análise de conteúdo. Tradução de Luís Antero Reto e Augusto Pinheiro. São Paulo: Edições 70, 2011.

BRASIL. Senado Federal. Lei de diretrizes e bases da educação. Dispositivos constitucionais pertinentes. Lei $\mathrm{n}^{\circ}$ 9.394, de 20 de dezembro de 1996. Regulamentações - Normas correlatas. Índice de assuntos e entidades. 5 ed. Brasília: Brasília, 2009. 
FIGUEIREDO, Juliana de Lima. Sociologia no ensino médio: representações dos alunos da cidade do Natal. 2004. Monografia (Bacharelado em Ciências Sociais) - Universidade Federal do Rio Grande do Norte, Natal, RN, 2004.

GATTI, Bernardete A. Formação de professores no Brasil: características e problemas. Educ. Soc., Campinas, v. 31, n. 113, p. 1355-1379, out.-dez. 2010

GIDDENS, Anthony. Sociologia. Porto Alegre: Artmed, 2005.

HALL, Stuart. A identidade cultural na pós-modernidade. Tradução de Tomaz Tadeu da Silva, Guaracira Lopes Louro. 11 ed. Rio de Janeiro: DP\&A, 2006.

JODELET, Denise. Representações sociais: um domínio em expansão. In: JODELET, Denise (Org.). As representações sociais. Rio de Janeiro: EDUERJ, 2001.

LIMA, Andreza Maria de. Teoria do núcleo central das representações sociais: pressupostos básicos e aplicações no campo da Educação. In: MACHADO, Laêda Bezerra. (Org.). Incursões e investigações em representações sociais e educação. Recife: Ed. Universitária da UFPE, 2013.

LIRA, André Augusto Diniz. Entre memória e identidades sociais. INTERFACE - Revista do Centro de Ciências Sociais Aplicadas, Natal/RN, v. 01, n. 02, p. 73-81, jul./dez. 2004.

MEKSENAS, Paulo. Sociologia. São Paulo: Cortez, 1990. (Coleção magistério - $2^{\circ}$ grau. Série formação geral).

MELO, Elda Silva do Nascimento. Representação social do ensinar: a dimensão pedagógica do habitus professoral. 2009. 197 f. Tese (Doutorado em Educação) - Programa de Pós-Graduação em Educação, Universidade Federal do Rio Grande do Norte, Natal, RN, 2009.

MELO, Elda Silva do Nascimento; DOMINGOS SOBRINHO, Moisés. A formação docente no contexto atual e a representação social dos professores tecida no campo educacional. Revista Educação em Questão, Natal, v. 24, n. 10, p. 110-136, set./dez. 2005.

MORAES, A. C. Ensino de sociologia: periodização e campanha pela obrigatoriedade. Caderno Cedes, Campinas, v. 31, n. 85, p. 359-382, set./dez. 2011.

MORAES, A. C.; TOMAZI, N. D.; GUIMARÃES, E. F. Orientações curriculares nacionais para o ensino médio - Sociologia. Brasília: MEC-SEB, 2006.

MOSCOVICI, Serge. A Representação Social da Psicanálise. Rio de Janeiro: Zahar, 1978.

- Representações sociais: investigações em psicologia social. Tradução de Pedrinho A. Guareschi. 5 ed. Petropólis: Vozes, 2007.

. Prefácio. In: GUARESCHI, Pedrinho; JOVCHELOVITCH, Sandra (Orgs.). Textos em representações sociais. 12 ed. Petrópolis, RJ: Vozes, 2011. 

UFRN

NÓBREGA, Sheva Maria da. Sobre a teoria das representações sociais. In: PAREDES MOREIRA, Antônia Silva (Org.). Representações sociais: teoria e prática. João Pessoa: Universitária/Autor Associado, 2001.

PIMENTA, Selma Garrido. Formação de professores - saberes da docência e identidade do professor. Nuances: estudos sobre educação. Revista Eletrônica do Programa de Pós-Graduação em Educação e do Departamento de Educação da Faculdade de Ciências e Tecnologia/Unesp - Presidente Prudente, v. 03, n. 03, p. 5-14, set. 1997.

PIMENTA, Selma Garrido; LIMA, Maria do Socorro Lucena. Estágio e docência. 7 ed. São Paulo: Cortez, 2012.

SÁ, Celso Pereira de. A construção do objeto de pesquisa em representações sociais. Rio de Janeiro: EdUERJ, 1998.

Núcleo central das representações sociais. 2 ed. Petrópolis, RJ: Vozes, 1996.

SILVA, Ileizi Fiorelli. A sociologia no ensino médio: os desafios institucionais e epistemológicos para a consolidação da disciplina. Cronos: Revista do Programa de Pós-Graduação em Ciências Sociais da UFRN, Natal-RN, v. 8, n. 2, p. 403-427, jul./dez, 2007.

SILVA, Tânia Elias M. Trajetórias da sociologia brasileira: considerações históricas. Cronos: Revista do Programa de Pós-Graduação em Ciências Sociais da UFRN, Natal-RN, v. 8, n. 2, p. 429-450, jul./dez. 2007.

TARDIF, Maurice. Saberes profissionais dos professores e conhecimentos universitários: elementos para uma epistemologia da prática profissional dos professores e suas consequências em relação à formação para o magistério. Revista Brasileira de Educação. jan.- abr., 2000. 
Social Representations and Teaching Identity: a case study in teacher education in the social sciences at UFRN

\begin{abstract}
The current presence of sociology in Brazilian basic education is a new element for the subjects involved in the field including students in the teacher accreditation course in the social sciences at the Federal University at Rio Grande do Norte (UFRN). To understand how the elements learned during initial teacher education influences the construction of identity, the social representations these subjects construct about the teaching identity was studied to understand how they represent sociology teachers. To do so, we compared the elements of the central core of social representations of freshmen undergraduates and student teachers in the UFRN course. The theory of social representations and a structural approach were used as theoretical support and the free association of words technique as a methodological resource. The data analysis indicated that memory plays a crucial role in representational and identity construction, as familiarity with the discipline of sociology in high school brought new and important elements to the composition of the profile of the current freshmen in the teacher accreditation course studied.the profile of the current freshmen in bachelor investigated.
\end{abstract}

Keywords: Teacher identity. Teacher training. Social representations.

\section{Elda Silva do Nascimento Melo}

E-mail: eldasnmelo@hotmail.com

Karla Michelle de Oliveira

E-mail:kmioliv@gmail.com

\author{
Representaciones sociales $y$ identidad \\ docente: un estudio de caso en la formación \\ docente en ciencias sociales UFRN
}

\section{Resumen}

La presencia hoy de Sociología en la educación básica brasileña es un nuevo elemento para los temas relacionados a la misma y, para el grupo de profesores/as de la carrera de Ciencias Sociales de la Universidad Federal de Río Grande del Norte (UFRN), la situación no tiene es diferente. Con el objetivo de entender cómo los conocimientos aprendidos durante la formación inicial de los profesores influyeron en el proceso de construcción de la identidad, de esta forma, se investigó las representaciones sociales con que estos sujetos construyen la identidad docente, buscando comprender cómo estos chicos representan a los maestros sociología. Por lo tanto, se realizó una comparación entre los elementos que componen el núcleo central de las representaciones sociales de los estudiantes de primer año y los alumnos de ese curso. Se utilizó como referencia teórica de este estudio la Teoría de las Representaciones Sociales y el Abordaje Estructural, así cómo, la técnica de Asociación Libre de Palabras como recurso metodológico. Al llevar a cabo el análisis de los datos obtenidos durante la investigación, se hizo evidente que la memoria juega un papel crucial en los procesos de construcción de la representación y de la identidad, pues la familiaridad con la disciplina de Sociología en la escuela secundaria trajo elementos nuevos e importantes para la composición del perfil de los estudiantes de primer año del profesorado que se investigó.

Palabras clave: Identidad docente. La formación del profesorado. Representaciones sociales.

Enviado em: 30/05/2015

Versão final enviada em: 11/08/2016

Aprovado em: 10/10/2016 